\title{
Omeprazole does not Potentiate Acute Oxygen Toxicity in Fetal Human Pulmonary Microvascular Endothelial Cells Exposed to Hyperoxia
}

Ananddeep Patel, Shaojie Zhang, Bhagavatula Moorthy, and Binoy Shivanna*

Section of Neonatology, Department of Pediatrics, Baylor College of Medicine, Houston, Texas, USA

\begin{abstract}
Hyperoxia contributes to the pathogenesis of broncho-pulmonary dysplasia (BPD), which is a developmental lung disease of premature infants that is characterized by an interruption of lung alveolar and pulmonary vascular development. Omeprazole $(\mathrm{OM})$ is a proton pump inhibitor that is used to treat humans with gastric acid related disorders. Earlier we observed that OM-mediated aryl hydrocarbon receptor (AhR) activation attenuates acute hyperoxic lung injury in adult mice and oxygen toxicity in adult human lung cells. However, our later studies in newborn mice demonstrated that OM potentiates hyperoxia-induced developmental lung injury. Whether OM exerts a similar toxicity in primary human fetal lung cells is unknown. Hence, we tested the hypothesis that OM potentiates hyperoxia-induced cytotoxicity and ROS generation in the human fetal lung derived primary human pulmonary microvascular endothelial cells (HPMEC). OM activated AhR as evident by a dose-dependent increase in cytochrome P450 (CYP) 1A1 mRNA levels in OM-treated cells. Furthermore, OM at a concentration of $100 \mu \mathrm{M}$ (OM 100) increased NADP(H) quinone oxidoreductase 1 (NQO1) expression. Surprisingly, hyperoxia decreased rather than increase the NQO1 protein levels in OM 100-treated cells. Exposure to hyperoxia increased cytotoxicity and hydrogen peroxide $\left(\mathrm{H}_{2} \mathrm{O}_{2}\right)$ levels. Interestingly, OM 100-treated cells exposed to air had increased $\mathrm{H}_{2} \mathrm{O}_{2}$ levels. However, hyperoxia did not further augment $\mathrm{H}_{2} \mathrm{O}_{2}$ levels in OM 100-treated cells. Additionally, hyperoxia-mediated oxygen toxicity was similar in both vehicle- and OM-treated cells. These findings contradict our hypothesis and support the hypothesis that OM does not potentiate acute hyperoxic injury in HPMEC in vitro.
\end{abstract}

Keywords: Omeprazole; Aryl hydrocarbon receptor; Hyperoxia; Oxidant stress; Human pulmonary microvascular endothelial cells; Cytochrome P450 1A1; NADP $(\mathrm{H})$ quinone oxidoreductase 1

\section{Abbreviations}

AhR: Aryl Hydrocarbon Receptor; ARDS: Acute Respiratory Distress Syndrome; BPD: Broncho Pulmonary Dysplasia; CYP: Cytochrome P450; DMSO: Dimethylsulfoxide; HPMEC: Human Pulmonary Microvascular Endothelial Cells; $\mathrm{H}_{2} \mathrm{O}_{2}:$ Hydrogen Peroxide; MTT: 3-(4, 5-Dimethylthiazolyl-2)-2, 5-Diphenyltetrazolium Bromide; NQO1: NADP(H) Quinone Oxidoreductase 1; OM: Omeprazole; OM 5: Omeprazole $5 \mu \mathrm{M}$; OM 100: Omeprazole $100 \mu \mathrm{M}$; PPI: Proton Pump Inhibitor; ROS: Reactive Oxygen Species

\section{Introduction}

Although supplemental oxygen is commonly administered as a life-saving measure in patients with impaired lung function, it may also exacerbate lung injury [1]. Excessive oxygen exposure leads to increased reactive oxygen species (ROS) production and expression of pro-inflammatory cytokines [2], which can react with nearby macromolecules (e.g., protein, lipids, DNA, and RNA) and modify their structure and function [3], resulting in both acute and chronic pulmonary toxicities. The antioxidant defense system develops late in gestation, making preterm neonates highly susceptible to oxidative stress [4,5]. Despite significant advances in the management of premature neonates, broncho-pulmonary dysplasia (BPD) remains the most prevalent, and one of the most serious long-term sequelae of preterm birth, affecting approximately 14,000 preterm infants born each year in United States [6,7]. Hyperoxia-induced ROS generation is a major contributor to the development of BPD and its sequelae [8]. Infants with BPD are more likely to have long-term pulmonary problems, increased re-hospitalizations during the first year of life, and delayed neurodevelopment $[6,9]$. Hence, there is an urgent need for improved therapies in the prevention and treatment of BPD.
The aryl hydrocarbon receptor (AhR) is a member of basic - helix loop - helix / PER - ARNT - SIM family of transcriptional regulators [10-12]. In humans, the AhR is highly expressed in the lungs, thymus, kidney and liver [13]. The AhR is predominantly cytosolic, held in a core complex comprising two molecules of $90-\mathrm{kDa}$ heat shock protein and a single molecule of the co-chaperone hepatitis X-associated protein-2 $[14,15]$. AhR activation results in the translocation of the cytosolic AhR to the nucleus, where it dimerizes with the AhR nuclear translocator, to form a heterodimeric transcription factor. The heterodimeric transcription factor initiates transcription of many phase I and phase II detoxification enzymes such as cytochrome P450 (CYP) 1A1, CYP1A2, glutathione S-transferase- $\alpha, \mathrm{NAD}(\mathrm{P}) \mathrm{H}$ quinone reductase-1 (NQO1), UDP glucuronosyl transferase which are encoded by the $A h$ gene locus [16-19]. Studies from our laboratory and elsewhere have demonstrated that AhR is a crucial regulator of lung inflammation and oxidative stress in adult and newborn mice [20-23]. Furthermore, we observed that AhR deficiency potentiates oxygen toxicity in primary fetal human pulmonary microvascular endothelial cells (HPMEC) [24]. These observations indicate that AhR activation may be sufficient to protect newborn mice and primary human lung cells against oxygen toxicity.

*Corresponding author: Binoy Shivanna, Division of Neonatal-Perinatal Medicine Department of Pediatrics, Texas Children's Hospital, Baylor College of Medicine, 1102 Bates Avenue, MC: FC530.01, Houston, Texas 77030, Tel: 832-824-6474 Fax: 832-825-3204; E-mail: shivanna@bcm.edu

Received September 21, 2015; Accepted October 06, 2015; Published October 09, 2015

Citation: Patel A, Zhang S, Moorthy B, Shivanna B (2015) Omeprazole does not Potentiate Acute Oxygen Toxicity in Fetal Human Pulmonary Microvascular Endothelial Cells Exposed to Hyperoxia. Pharm Anal Acta 6: 424 doi: $10.4172 / 21532435.1000424$

Copyright: (c) 2015 Patel A, et al. This is an open-access article distributed under the terms of the Creative Commons Attribution License, which permits unrestricted use, distribution, and reproduction in any medium, provided the original author and source are credited. 
Hence, we investigated whether an AhR agonist such as omeprazole $(\mathrm{OM})$ can modulate hyperoxic lung injury in newborn animals and human lung cells.

Omeprazole, a substituted benzimidazole derivative, is a proton pump inhibitor (PPI) that inhibits gastric acid secretion in humans [25] and is used to treat gastric acid related disorders in humans [26]. $\mathrm{OM}$ is known to activate AhR in adult humans and rodents [27-32]. Hence, we investigated whether OM can activate AhR and attenuate hyperoxia-induced developmental lung injury in newborn mice. To our surprise, long-term OM therapy potentiated hyperoxic lung injury in newborn mice and these harmful effects was associated with decreased AhR activation [33]. Whether short-term OM therapy potentiates oxygen toxicity in primary human fetal lung cells is unknown. The goals of this study, therefore, were to investigate the effects of shortterm OM therapy in fetal HPMEC exposed to acute hyperoxia. We specifically chose HPMEC because they are widely used to determine the mechanisms of neonatal lung injury $[34,35]$. Using these cells, we tested the hypothesis that OM potentiates acute hyperoxia-induced cytotoxicity and ROS generation in primary human fetal lung cells in vitro.

\section{Materials and Methods}

\section{Cell culture and treatment}

Human pulmonary microvascular endothelial cells (HPMEC), the primary microvascular endothelial cells derived from the lungs of human fetus were obtained from ScienCell research laboratories (San Diego, CA; 3000). HPMEC were grown in $95 \%$ air and $5 \% \mathrm{CO}_{2}$ at $37^{\circ} \mathrm{C}$ in specific endothelial cell medium according to the manufacturer's protocol. Cells were treated with either dimethylsulfoxide (DMSO) (Sigma-Aldrich, St. Louis, MO; 276855) or OM at varying concentrations up to $100 \mu \mathrm{M}$ (Sigma-Aldrich, St. Louis, MO; O104) for $2 \mathrm{~h}$, followed by exposure to air or hyperoxia for up to $48 \mathrm{~h}$.

\section{Determination of functional activation of the AhR}

It is widely established that functional activation of AhR results in its translocation into the nucleus, which results in transcriptional activation of the phase I enzyme, CYP1A1. Therefore, we determined the functional activation of AhR by analyzing the expression of CYP1A1 mRNA levels.

\section{Western blot assays}

Whole-cell protein extracts from the cells treated with DMSO or $\mathrm{OM}$ and exposed to air or hyperoxia was obtained by using nuclear extraction kit (Active Motif, Carlsbad, CA; 40010) according to the manufacturer's instructions [31]. $\beta$-actin was used as the reference protein. The protein extracts were separated by $10 \%$ SDSpolyacrylamide gel electrophoresis and transferred to polyvinylidene difluoride membranes. The membranes were incubated overnight at $4^{\circ} \mathrm{C}$ with the following primary antibodies: anti-NQO1 (Santa Cruz Biotechnologies, Santa Cruz, CA; sc-16464, dilution 1:500) and anti- $\beta$-actin (Santa Cruz Biotechnologies, Santa Cruz, CA; sc-47778, dilution 1:1000) antibodies. The primary antibodies were detected by incubation with the appropriate horseradish peroxidase-conjugated secondary antibodies. The immunoreactive bands were detected by chemiluminescence methods and the band density was analyzed by Image J software (National Institutes of Health, Bethesda, MD).

\section{Real-time RT-PCR assays}

Cells were grown on 6 well plates to 50-60 \% confluence, after which they were treated with DMSO or OM, and exposed to air for $24 \mathrm{~h}$, following which the total RNA was isolated and reverse transcribed to cDNA as mentioned before [31]. Real-time quantitative RT-PCR analysis was performed with 7900HT Real-Time PCR System using iTaq Universal SYBR Green Supermix (Biorad, Hercules, CA; 1725121). The sequences of the primer pairs were $h C Y P 1 A 1$ : 5'-TGGATGAGAACGCCAATGTC-3' and 5'-TGGGTTGACCCATAGCTTCT-3'; $h N Q O 1$ : 5'-ACGCCC-GAATTCAAATCCT-3' and 5'-CCTGCCTGGAAGTTTAGGTCAA-3'; $h \beta$-actin: 5'-TGACGTGGACATCCGCAAAG-3' and 5'-CTGGAAGGTGGACAGCGAGG-3'. $\beta$-actin was used as the reference gene. The $\Delta \Delta \mathrm{C}_{\mathrm{t}}$ method was used to calculate the fold change in mRNA expression: $\Delta \mathrm{C}_{t}=\mathrm{C}_{t}$ (target gene) - $\mathrm{C}_{\mathrm{t}}$ (reference gene), $\Delta \Delta \mathrm{C}_{\mathrm{t}}=$ $\Delta \mathrm{C}_{\mathrm{t}}$ (treatment) $-\Delta \mathrm{C}_{\mathrm{t}}$ (control), fold change $=2^{(-\Delta \Delta \mathrm{Ct})}$.

\section{Exposure of cells to hyperoxia}

Hyperoxia experiments were conducted in a plexiglass, sealed chamber into which a mixture of $95 \% \mathrm{O}_{2}$ and $5 \% \mathrm{CO}_{2}$ was circulated continuously. The chamber was placed in a Forma Scientific waterjacketed incubator at $37^{\circ} \mathrm{C}$. Once the $\mathrm{O}_{2}$ level inside the chamber reached $95 \%$, the cells were placed inside the chamber for the desired length of time.

\section{Cell viability assay}

Cell viability was determined by a colorimetric assay based on the ability of viable cells to reduce the tetrazolium salt, MTT (3(4, 5-dimethylthiazolyl-2)-2, 5-diphenyltetrazolium bromide), to formazan. HPMEC were seeded onto 96-well microplates, treated with DMSO or OM, followed by exposure to air or hyperoxia for up to $48 \mathrm{~h}$. The cell viability was then assessed by MTT reduction assays as outlined in the MTT Assay protocol (American Type Culture Collection, Manassas, VA).

\section{Cell proliferation assay}

Cell proliferation was determined based on the measurement of cellular DNA content via fluorescent dye binding using the CyQUANT NF cell proliferation assay kit (Invitrogen, Carlsbad, CA; C35006) as per the manufacturer's recommendations. HPMEC seeded onto 96-well microplates were treated with DMSO or OM, followed by exposure to air or hyperoxia for up to $48 \mathrm{~h}$. At the end of experiments, the medium was gently aspirated, and the cells were incubated for 30 minutes with $100 \mu \mathrm{l}$ of $1 \mathrm{X}$ dye binding solution per well. Following the incubation, the fluorescence intensity of each sample was measured using Spectramax M3 fluorescence microplate reader with excitation at $485 \mathrm{~nm}$ and emission detection at $530 \mathrm{~nm}$.

\section{Measurement of $\mathrm{H}_{2} \mathrm{O}_{2}$ generation}

Hydrogen peroxide $\left(\mathrm{H}_{2} \mathrm{O}_{2}\right)$ levels was quantified by the ROS$\mathrm{Glo}^{\mathrm{Tx}} \mathrm{H}_{2} \mathrm{O}_{2}$ Assay (Promega, Madison, WI; G8820) according to the manufacturer's recommendation. Briefly, cells were grown on 96-well plates to $60-70 \%$ confluence, after which they were treated with DMSO or OM, and exposed to air or hyperoxia for up to $24 \mathrm{~h}$. Six-hours prior to the completion of experiments, the $\mathrm{H}_{2} \mathrm{O}_{2}$ substrate was added to the wells and the cell culture plates were returned to their respective exposure conditions for the final $6 \mathrm{~h}$ of the experiment. At the end of experiments, ROS-Glo ${ }^{\text {tw }}$ detection solution was added to each well, following which the cells were incubated for 20 minutes at room temperature before the relative luminescence units was measured using Spectramax M3 luminescence microplate reader. 
Citation: Patel A, Zhang S, Moorthy B, Shivanna B (2015) Omeprazole does not Potentiate Acute Oxygen Toxicity in Fetal Human Pulmonary Microvascular Endothelial Cells Exposed to Hyperoxia. Pharm Anal Acta 6: 424. doi:10.4172/21532435.1000424

\section{Analyses of data}

The results were analyzed by GraphPad Prism 5 software. At least three separate experiments were performed for each measurement, and the data are expressed as means \pm SEM. The effects of $\mathrm{OM}$ and hyperoxia and their associated interactions for the outcome variables were assessed using ANOVA techniques. Multiple comparisons testing by the posthoc Bonferroni test was performed if statistical significance of either variable or interaction was noted by ANOVA. A $p$ value of $<0.05$ was considered significant.

\section{Results}

In this study, we investigated the impact of OM on acute hyperoxic injury in the human fetal lung derived HPMEC in vitro.

\section{Omeprazole increases CYP1A1 and NQO1 expression in HPMEC}

It has been well documented that activation of AhR results in its translocation from the cytoplasm to the nucleus and results in transcriptional activation of the prototypical target gene, CYP1A1. Hence, we determined the effects of OM on CYP1A1 mRNA levels by real-time RT-PCR analysis. OM significantly increased CYP1A1 mRNA levels (Figure 1A) in a dose-dependent manner. We also determined the effects of OM on NQO1 expression since our earlier study indicated that this enzyme was down-regulated in AhR-deficient HPMEC [24]. Interestingly, OM increased NQO1 mRNA (Figure 1B) and protein levels (Figure 1C and 1D).

\section{Omeprazole does not potentiate hyperoxia-induced cytotoxicity in HPMEC}

The MTT activity reflects the mitochondrial activity of the cells, and thus the absorbance measured reflects the cell viability. Hyperoxia decreased cell viability, as reflected by a decline in the cellular capacities to reduce MTT (Figure 2A). Since oxidant-stress such as hyperoxia is well known to inhibit cell proliferation in general, we next determined its effects on cell proliferation. As expected, CyQUANT NF cell proliferation assay showed that hyperoxia inhibited proliferation of HPMEC (Figure 2B). However, OM did not potentiate hyperoxiainduced cytotoxicity (cell viability and proliferation) (Figure 2).

Omeprazole does not increase hyperoxia-induced $\mathrm{H}_{2} \mathrm{O}_{2}$ generation in HPMEC

Hyperoxia-induced generation of ROS has been widely implicated in the pathogenesis of hyperoxic lung injury. To determine whether OM regulates ROS production, $\mathrm{H}_{2} \mathrm{O}_{2}$ levels was measured by ROS-Glo ${ }^{\mathrm{mm}}$ $\mathrm{H}_{2} \mathrm{O}_{2}$ assay. As expected, hyperoxia increased $\mathrm{H}_{2} \mathrm{O}_{2}$ levels in vehicleand $\mathrm{OM} 5$-treated cells (Figure 3). Interestingly, $\mathrm{OM}$ at a concentration of $100 \mu \mathrm{M}$ increased $\mathrm{H}_{2} \mathrm{O}_{2}$ levels in HPMEC in air conditions (Figure 3). However, hyperoxia did not augment $\mathrm{H}_{2} \mathrm{O}_{2}$ levels in OM 100-treated cells and in fact, the $\mathrm{H}_{2} \mathrm{O}_{2}$ levels were decreased in hyperoxic- compared to air-conditions in OM 100-treated cells (Figure 3).

\section{Omeprazole does not augment hyperoxia-induced increase in NQO1 expression in HPMEC}

It is well established that phase I and II enzymes such as CYP1A1 and NQO1 attenuate hyperoxia-induced cytotoxicity. However, OM 100-treated cells failed to attenuate hyperoxia-induced cytotoxicity despite inducing the cytoprotective enzyme, NQO1, in HPMEC exposed to air. Hence, we determined the effects of OM on NQO1 protein expression in hyperoxic conditions. Hyperoxia increased
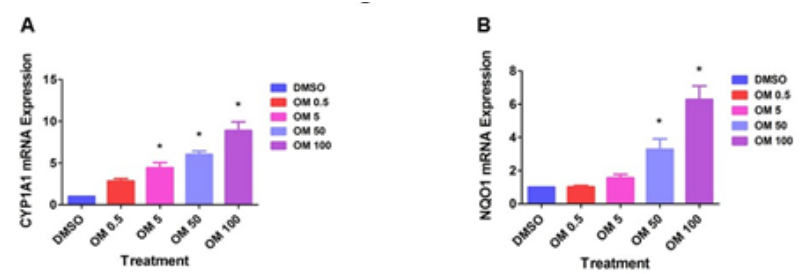

C



Figure 1: Omeprazole-treated HPMEC display increased CYP1A1 and NQO1 expression: Human pulmonary microvascular endothelial cells (HPMEC) were treated with dimethylsulfoxide (DMSO) or omeprazole (OM) at concentrations of 0.5 (OM 0.5), 5 (OM 5), 50 (OM 50) or 100 (OM 100) $\mu \mathrm{M}$ for up to $48 \mathrm{~h}$, following which: RNA was extracted for CYP1A1 (A) and NQO1 (B) mRNA expression; and whole-cell protein was extracted for immunoblotting using anti-NQO1 or $\beta$-actin antibodies (C). Densitometric analyses wherein NQO1 band intensities were quantified and normalized to $\beta$-actin (D). Data are representative of at least three independent experiments. Values are presented as means $\pm \operatorname{SEM}(n=3) .{ }^{*}$, $p<0.05$ vs. DMSO-treated cells.

NQO1 protein expression in vehicle- and OM 5-treated cells (Figure 4A and $4 \mathrm{~B}$ ). Consistent with its effect on $\mathrm{H}_{2} \mathrm{O}_{2}$ levels, hyperoxia decreased rather than increase the NQO1 protein levels in OM 100-treated cells (Figure $4 \mathrm{~A}$ and $4 \mathrm{~B}$ ).

\section{Discussion}

The present study demonstrates that the PPI, OM, does not potentiate acute hyperoxic injury in vitro. In human fetal lung-derived HPMEC in vitro, although OM 100 induced the cytoprotective enzyme, NQO1 in air conditions, it failed to augment hyperoxia-induced increase in NQO1 expression and protect against hyperoxia-induced cytotoxicity.

Studies from our laboratory and others have reported that AhR may be a crucial regulator of oxidant stress and inflammation through the induction of several detoxifying enzymes or via "cross-talk" with other signal transduction pathways and $\mathrm{OM}$ has shown to activate AhR. Additionally, we observed that $\mathrm{OM}$ attenuates hyperoxic injury in the adult human lung cell line, H441 cells in vitro [31]. However, we observed contrasting effects of OM on hyperoxia-induced lung pathology in newborn and adult mice $[32,33]$. Therefore, we conducted experiments with OM in human fetal lung derived HPMEC in vitro, to investigate whether OM modulates acute hyperoxic injury in primary human fetal lung cells.

Initially, we studied the interaction between $\mathrm{OM}$ and AhR Functional activation of $\mathrm{AhR}$ results in its translocation into the nucleus, which causes transcriptional activation of the AhR gene battery that includes phase I and II detoxification enzymes such as CYP $1 \mathrm{~A} 1$ and NQO1 [17-19,36]. Therefore, we analyzed the expression of the phase I and II enzymes to determine the functional activation of the AhR. The concentration-dependent increases in CYP1A1 and NQO1 mRNA expression in OM-treated cells exposed to air (Figure 1A and 1B), indicates that OM transcriptionally activates CYP1A1 and NQO1 enzymes. Upon further investigation of the concentration specific effects of OM on CYP1A1 and NQO1 mRNA expression (Figure 1A), 
Citation: Patel A, Zhang S, Moorthy B, Shivanna B (2015) Omeprazole does not Potentiate Acute Oxygen Toxicity in Fetal Human Pulmonary Microvascular Endothelial Cells Exposed to Hyperoxia. Pharm Anal Acta 6: 424. doi:10.4172/21532435.1000424

we have observed that OM induces NQO1 via AhR-independent, but Nrf2-dependent mechanisms (manuscript under review).

Next, we studied the effects of OM on cell viability and cell proliferation in HPMEC exposed to hyperoxia. Evidence suggests that exposure to hyperoxia results in increased generation of ROS [37], and decreased cell proliferation [38,39] and viability [40]. Although the mechanism(s) are unclear, increased ROS levels have been thought to contribute to acute and chronic lung disease in humans by inhibiting cell proliferation and increasing cell death by apoptosis or necrosis [41]. Similarly, we observed increased $\mathrm{H}_{2} \mathrm{O}_{2}$ generation (Figure 3) and decreased cell viability (Figure $2 \mathrm{~A}$ ) and proliferation (Figure 2B) in hyperoxia-exposed HPMEC. However, OM did not augment hyperoxia-induced cytotoxicity (Figure 2), which supports the concept that short-term OM therapy does not potentiate acute oxygen toxicity in HPMEC. Importantly, higher OM concentrations increased $\mathrm{H}_{2} \mathrm{O}_{2}$ levels in air conditions (Figure 3). However, the $\mathrm{H}_{2} \mathrm{O}_{2}$ levels in fact decreased in OM 100-treated cells exposed to hyperoxia (Figure 3). The mechanisms of these interesting findings are unknown at this time point and warrants further investigation.

Our recent study in newborn mice suggest that OM therapy potentiates hyperoxia-induced developmental lung injury [33]. However our observations in this study disprove our hypothesis that $\mathrm{OM}$ potentiates acute hyperoxic injury in human fetal lung cells. The most plausible reason for these results may be related to the duration of OM therapy wherein we exposed human lung cells for a shorter duration (days) compared to the prolonged duration (weeks) in newborn mice. Some of the other contributory factors may be due to differences in the species and the cell type being studied.

To address the unexpected finding of the failure of OM to protect cells against hyperoxia-induced cytotoxicity despite inducing NQO1 in air conditions (Figure 1B, 1C and 1D), we determined the effects of OM therapy on NQO1 expression in hyperoxia-exposed cells. Surprisingly, hyperoxia decreased rather than the expected increase in NQO1 expression in OM 100-treated cells (Figure 4). Although the molecular mechanisms of these observations is beyond the scope of this study, it might be related to factors that may competitively inhibit the transcription of NQO1 gene at the promoter level or an altered miRNA profile that can inhibit the translation of NQO1 gene in OM 100-treated cells exposed to hyperoxia.

Hyperoxia-induced expression of the phase I and II enzymes have been observed by several other investigators both in adult $[20,21,42,43]$ and newborn [44,45] rodents and human fetal lung cells [24]. This phenomenon might be a protective responsive to oxidative stress because of its striking resemblance to the effects of hyperoxia on the "classic" AOE such as superoxide dismutase, glutathione peroxidase, glutathione reductase, and catalase [46,47]. Furthermore, decreased expression of phase I and II enzymes in newborn AhRd mice and AhR-deficient human lung cells compared to wild type controls was associated with increased hyperoxic injury in our previous studies $[23,24]$, which suggests that the effects of hyperoxia on these enzymes are a compensatory rather than a contributory response. NQO1 has been shown to protect cells and tissues against oxidant injury induced by various toxic chemicals [48] and oxygen [43,45,49]. The protective mechanisms of these enzymes have been attributed to their ability to conjugate and scavenge the reactive electrophiles and lipid peroxidation products generated by an oxidant injury $[43,50]$. The lack of OM 100-mediated protection against acute oxygen toxicity despite inducing NQO1 in air condition may be attributed at least in part due to its failure to increase the cytoprotective NQO1 enzyme levels in hyperoxic conditions (Figure 4).
In summary, we demonstrate that short-term OM therapy does not potentiate acute hyperoxia induced: (i) decrease in cell viability (Figure 2A); (ii) inhibition of cell proliferation (Figure 2B); and (iii) ROS generation (Figure 3) in HPMEC in vitro. Although, OM has a proven safety profile in humans for over decades and we did not observe any toxic effects with $\mathrm{OM}$ at concentrations similar to the blood concentrations $(5 \mu \mathrm{M})$ documented in humans following $\mathrm{OM}$ therapy [51], it significantly increased $\mathrm{H}_{2} \mathrm{O}_{2}$ levels in air conditions (Figure 3 ) at a higher concentration $(100 \mu \mathrm{M})$. Hence, we propose that there is a need to exert caution before instituting long-term high dose $\mathrm{OM}$ therapy in premature infants.

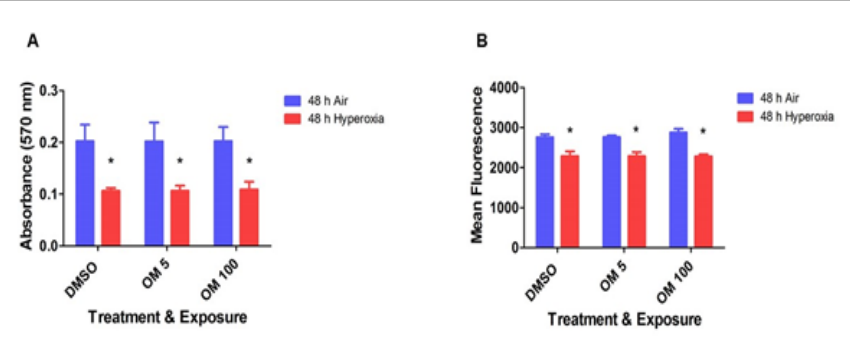

Figure 2: Effects of OM on hyperoxia-induced cytotoxicity in HPMEC: Human pulmonary microvascular endothelial cells (HPMEC) treated with DMSO, OM 5 or OM 100 were exposed to air or hyperoxia for up to $48 \mathrm{~h}$, following which: (A) Cell viability was assessed by MTT (3-(4, 5-dimethylthiazolyl-2)-2, 5-diphenyltetrazolium bromide) reduction activities; and (B) Cell proliferation was determined based on the measurement of cellular DNA content via fluorescent dye binding using the CyQUANT NF cell proliferation assay. Data are representative of at least three independent experiments. Values are presented as means \pm SEM $(n=3)$. Two-way ANOVA showed an effect of hyperoxia but not of $\mathrm{OM}$ treatment for the dependent variables, cell viability and proliferation, in this figure. Significant differences between air- and hyperoxia-exposed cells are indicated by * $p<0.05$.

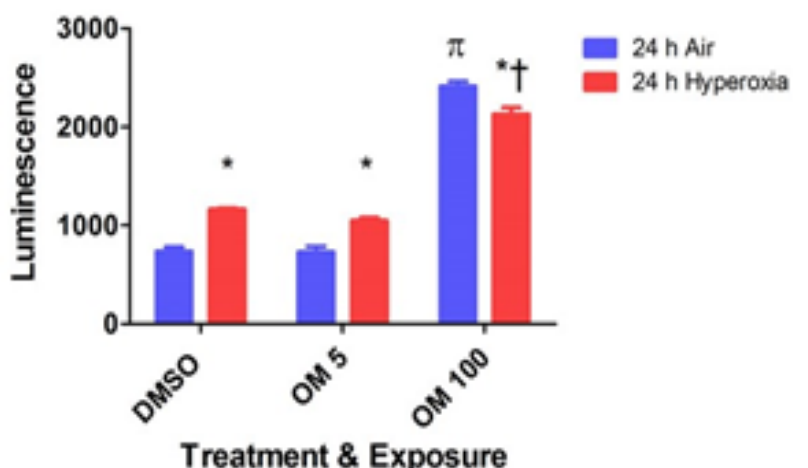

Figure 3: Effects of OM on hyperoxia-induced $\mathrm{H}_{2} \mathrm{O}_{2}$ generation in HPMEC Human pulmonary microvascular endothelial cells (HPMEC) treated with DMSO, OM 5, or OM 100 were exposed to air or hyperoxia for up to $24 \mathrm{~h}$, following which the $\mathrm{H}_{2} \mathrm{O}_{2}$ levels was measured by ROS-Glo ${ }^{\mathrm{TM}} \mathrm{H}_{2} \mathrm{O}_{2}$ assay. Data are representative of at least three independent experiments. Values are presented as means \pm SEM $(n=3)$. Two-way ANOVA showed an effect of hyperoxia and OM 100 and an interaction between them for the dependent variable, $\mathrm{H}_{2} \mathrm{O}_{2}$ levels, in this figure. Significant differences between air- and hyperoxia-exposed cells are indicated by *, $p<0.05$. Significant differences between hyperoxia-exposed DMSO-, OM 5-, and OM 100-treated cells are indicated by,$+ \mathrm{p}<0.05$. Significant differences between air-exposed DMSO-, OM 5-, and OM 100-treated cells are indicated by $\pi, p<0.05$. 
A

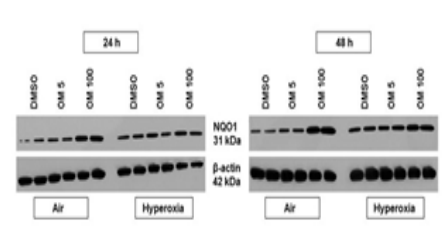

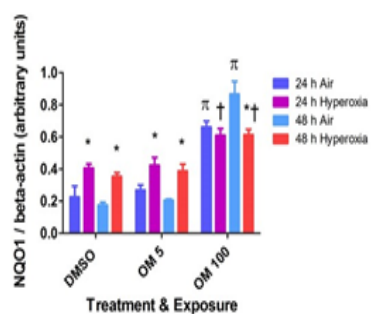

Figure 4: Effects of OM on NQO1 protein expression in hyperoxia-exposed HPMEC: Human pulmonary microvascular endothelial cells (HPMEC) were treated with DMSO, OM 5, or OM 100 for up to $48 \mathrm{~h}$, following which whole-cell protein was extracted for immunoblotting using anti-NQO1 or $\beta$-actin antibodies (A). Densitometric analyses wherein NQO1 band intensities were quantified and normalized to $\beta$-actin (B). Values are presented as means \pm SEM $(n=3)$. Two-way ANOVA showed an effect of hyperoxia and OM 100 and an interaction between them for the dependent variable, NQO1 protein levels, in this figure. Significant differences between air- and hyperoxia-exposed cells are indicated by *, $\mathrm{p}<0.05$. Significant differences between hyperoxia-exposed DMSO-, OM $5-$, and $\mathrm{OM} 100-$ treated cells are indicated by $t, p<0.05$. Significant differences between air-exposed DMSO-, OM 5-, and OM 100-treated cells are indicated by $\pi, p<0.05$.

\section{Funding Information}

This work was supported by grants from National Institutes of Health [K08 HD073323 to B.S. and R01 ES009132, R01 HL112516, R01 HL087174, and R01 ES019689 to B.M.]; and American Heart Association [BGIA 20190008 to B.S]. The study sponsors had no involvement in study design, data collection, analysis and interpretation, writing of the report or decision to submit the paper for publication.

\section{References}

1. Thiel M, Chouker A, Ohta A, Jackson E, Caldwell C, et al. (2005) Oxygenation inhibits the physiological tissue-protecting mechanism and thereby exacerbates acute inflammatory lung injury. PLoS Biol 3: e174.

2. Jobe AH, Hillman N, Polglase G, Kramer BW, Kallapur S, et al. (2008) Injury and inflammation from resuscitation of the preterm infant. Neonatology 94: 190196

3. Bhandari V, Choo-Wing R, Lee CG, Zhu Z, Nedrelow JH, et al. (2006) Hyperoxia causes angiopoietin 2-mediated acute lung injury and necrotic cell death. Nat Med 12: 1286-1293.

4. Vina J, Vento M, García-Sala F, Puertes IR, Gascó E, et al. (1995) L-cysteine and glutathione metabolism are impaired in premature infants due to cystathionase deficiency. Am J Clin Nutr 61: 1067-1069.

5. Asikainen TM, White CW (2005) Antioxidant defenses in the preterm lung: Role for hypoxia-inducible factors in BPD? Toxicol Appl Pharmacol 203: 177-188.

6. Fanaroff AA, Stoll BJ, Wright LL, Carlo WA, Ehrenkranz RA (2007) Trends in neonatal morbidity and mortality for very low birthweight infants. Am J Obstet Gynecol 196: e1-8.

7. Van Marter LJ (2009) Epidemiology of bronchopulmonary dysplasia. Semin Fetal Neonatal Med 14: 358-366.

8. Saugstad OD (2003) Bronchopulmonary dysplasia-oxidative stress and antioxidants. Semin Neonatol 8: 39-49.

9. Short EJ, Klein NK, Lewis BA, Fulton S, Eisengart S (2003) Cognitive and academic consequences of bronchopulmonary dysplasia and very low birth weight: 8-year-old outcomes. Pediatrics 112: e359.

10. Burbach KM, Poland A, Bradfield CA (1992) Cloning of the Ah-receptor cDNA reveals a distinctive ligand-activated transcription factor. Proc Natl Acad Sci U S A 89: 8185-8189.

11. Sogawa K, Fujii-Kuriyama $Y$ (1997) Ah receptor, a novel ligand-activated transcription factor. J Biochem 122: 1075-1079.
12. Beischlag TV, Luis Morales J, Hollingshead BD, Perdew GH (2008) The ary hydrocarbon receptor complex and the control of gene expression. Crit Rev Eukaryot Gene Expr 18: 207-250.

13. Tirona RG, Kim RB (2005) Nuclear receptors and drug disposition gene regulation. J Pharm Sci 94: 1169-1186.

14. Denis M, Cuthill S, Wikström AC, Poellinger L, Gustafsson JA (1988) Association of the dioxin receptor with the Mr 90,000 heat shock protein: A structural kinship with the glucocorticoid receptor. Biochem Biophys Res Commun 155: 801-807.

15. Carver LA, Bradfield CA (1997) Ligand-dependent interaction of the ary hydrocarbon receptor with a novel immunophilin homolog in vivo. J Biol Chem 272: 11452-11456

16. Emi Y, Ikushiro S, lyanagi T (1996) Xenobiotic responsive element-mediated transcriptional activation in the UDP-glucuronosyltransferase family 1 gene complex. J Biol Chem 271: 3952-3958.

17. Favreau LV, Pickett CB (1991) Transcriptional regulation of the rat $N A D(P) H$ Quinone reductase gene. Identification of regulatory elements controlling basal level expression and inducible expression by planar aromatic compounds and phenolic antioxidants. J Biol Chem 266: 4556-4561.

18. Fujisawa-Sehara A, Sogawa K, Yamane M, Fujii-Kuriyama Y (1987) Characterization of xenobiotic responsive elements upstream from the drugmetabolizing cytochrome P-450c gene: A similarity to glucocorticoid regulatory elements. Nucleic acids research 15: 4179-4191.

19. Rushmore TH, King RG, Paulson KE, Pickett CB (1990) Regulation of glutathione S-transferase $\mathrm{Ya}$ subunit gene expression: Identification of a unique xenobiotic-responsive element controlling inducible expression by planar aromatic compounds. Proc Natl Acad Sci U S A 87: 3826-3830.

20. Jiang W, Welty SE, Couroucli XI, Barrios R, Kondraganti SR (2004) Disruption of the Ah receptor gene alters the susceptibility of mice to oxygen-mediated regulation of pulmonary and hepatic cytochromes P4501A expression and exacerbates hyperoxic lung injury. The Journal of pharmacology and experimental therapeutics 310: 512-519.

21. Couroucli XI, Welty SE, Geske RS, Moorthy B (2002) Regulation of pulmonary and hepatic cytochrome P4501A expression in the rat by hyperoxia: Implications for hyperoxic lung injury. Mol Pharmacol 61: 507-515.

22. Thatcher TH, Maggirwar SB, Baglole CJ, Lakatos HF, Gasiewicz TA (2007) Aryl hydrocarbon receptor-deficient mice develop heightened inflammatory responses to cigarette smoke and endotoxin associated with rapid loss of the nuclear factor-kappaB component RelB. Am J Pathol 170: 855-864.

23. Shivanna B, Zhang W, Jiang W, Welty SE, Couroucli XI (2013) Functional deficiency of aryl hydrocarbon receptor augments oxygen toxicity-induced alveolar simplification in newborn mice. Toxicology and applied pharmacology 267: 209-217.

24. Zhang S, Patel A, Chu C, Jiang W, Wang L (2015) Aryl hydrocarbon receptor is necessary to protect fetal human pulmonary microvascular endothelial cells against hyperoxic injury: Mechanistic roles of antioxidant enzymes and ReIB. Toxicol Appl Pharmacol 286: 92-101.

25. Lind T, Cederberg C, Ekenved G, Haglund U, Olbe L (1983) Effect of omeprazole--a gastric proton pump inhibitor--on pentagastrin stimulated acid secretion in man. Gut 24: 270-276.

26. Li XQ, Andersson TB, Ahlström M, Weidolf $L$ (2004) Comparison of inhibitory effects of the proton pump-inhibiting drugs omeprazole, esomeprazole, lansoprazole, pantoprazole, and rabeprazole on human cytochrome P450 activities. Drug Metab Dispos 32: 821-827.

27. Quattrochi LC, Tukey RH (1993) Nuclear uptake of the Ah (dioxin) receptor in response to omeprazole: transcriptional activation of the human CYP1A1 gene. Mol Pharmacol 43: 504-508.

28. Backlund M, Ingelman-Sundberg M (2005) Regulation of aryl hydrocarbon receptor signal transduction by protein tyrosine kinases. Cell Signal 17: 39-48.

29. Murray IA, Perdew GH (2008) Omeprazole stimulates the induction of human insulin-like growth factor binding protein-1 through aryl hydrocarbon receptor activation. The Journal of pharmacology and experimental therapeutics 324:1102-1110.

30. Yoshinari K, Ueda R, Kusano K, Yoshimura T, Nagata K (2008) Omeprazole transactivates human CYP1A1 and CYP1A2 expression through the common regulatory region containing multiple xenobiotic-responsive elements. Biochem Pharmacol 76: 139-145. 
Citation: Patel A, Zhang S, Moorthy B, Shivanna B (2015) Omeprazole does not Potentiate Acute Oxygen Toxicity in Fetal Human Pulmonary Microvascular Endothelial Cells Exposed to Hyperoxia. Pharm Anal Acta 6: 424. doi:10.4172/21532435.1000424

31. Shivanna B, Chu C, Welty SE, Jiang W, Wang L, et al. (2011) Omeprazole attenuates hyperoxic injury in $\mathrm{H} 441$ cells via the aryl hydrocarbon receptor. Free Radic Biol Med 51: 1910-1917.

32. Shivanna B, Jiang W, Wang L, Couroucli XI, Moorthy B (2011) Omeprazole attenuates hyperoxic lung injury in mice via aryl hydrocarbon receptor activation and is associated with increased expression of cytochrome P4501A enzymes. J Pharmacol Exp Ther 339: 106-114.

33. Shivanna B, Zhang S, Patel A, Jiang W, Wang L (2015) Omeprazole Attenuates Pulmonary Aryl hydrocarbon Receptor Activation and Potentiates HyperoxiaInduced Developmental Lung Injury in Newborn Mice. Toxicol Sci.

34. Wright CJ, Agboke F, Chen F, LA P, Yang G (2010) NO inhibits hyperoxiainduced NF-kappaB activation in neonatal pulmonary microvascular endothelial cells. Pediatric research 68: 484-489.

35. Menden H, Tate E, Hogg N, Sampath V (2013) LPS-mediated endothelia activation in pulmonary endothelial cells: Role of Nox2-dependent IKK-beta phosphorylation. American journal of physiology. Lung cellular and molecular physiology 304: L445-455.

36. Whitlock JP Jr (1999) Induction of cytochrome P4501A1. Annu Rev Pharmaco Toxicol 39: 103-125.

37. Budinger GR, Tso M, McClintock DS, Dean DA, Sznajder JI, et al. (2002) Hyperoxia-induced apoptosis does not require mitochondrial reactive oxygen species and is regulated by Bcl-2 proteins. J Biol Chem 277: 15654-15660.

38. Ogunlesi F, Cho C, McGrath-Morrow SA (2004) The effect of glutamine on A549 cells exposed to moderate hyperoxia. Biochim Biophys Acta 1688: 112 120.

39. Yee M, Vitiello PF, Roper JM, Staversky RJ, Wright TW (2006) Type II epithelia cells are critical target for hyperoxia-mediated impairment of postnatal lung development. American journal of physiology. Lung cellular and molecular physiology 291: L1101-1111.

40. Bhakta KY, Jiang W, Couroucli XI, Fazili IS, Muthiah K, et al. (2008) Regulation of cytochrome P4501A1 expression by hyperoxia in human lung cell lines: Implications for hyperoxic lung injury. Toxicol Appl Pharmacol 233: 169-178.
41. Schoonen WG, Wanamarta AH, van der Klei-van Moorsel JM, Jakobs C Joenje $H(1990)$ Hyperoxia-induced clonogenic killing of HeLa cells associated with respiratory failure and selective inactivation of Krebs cycle enzymes. Mutat Res 237: 173-181.

42. Moorthy B, Nguyen UT, Gupta S, Stewart KD, Welty SE, et al. (1997) Induction and decline of hepatic cytochromes P4501A1 and $1 \mathrm{~A} 2$ in rats exposed to hyperoxia are not paralleled by changes in glutathione S-transferase-alpha. Toxicol Lett 90: 67-75.

43. Cho HY, Jedlicka AE, Reddy SP, Kensler TW, Yamamoto M, et al. (2002) Role of NRF2 in protection against hyperoxic lung injury in mice. Am J Respir Cell Mol Biol 26: 175-182.

44. Couroucli XI, Liang YH, Jiang W, Wang L, Barrios R (2011) Prenata administration of the cytochrome P4501A inducer, Beta-naphthoflavone (BNF), attenuates hyperoxic lung injury in newborn mice: implications for bronchopulmonary dysplasia (BPD) in premature infants. Toxicol App Pharmacol 256: 83-94.

45. McGrath-Morrow S, Lauer T, Yee M, Neptune E, Podowski M, et al. (2009) Nrf2 increases survival and attenuates alveolar growth inhibition in neonatal mice exposed to hyperoxia. Am J Physiol Lung Cell Mol Physiol 296: L565-573.

46. Ho YS, Dey MS, Crapo JD (1996) Antioxidant enzyme expression in rat lungs during hyperoxia. Am J Physiol 270: L810-818.

47. Clerch LB (2000) Post-transcriptional regulation of lung antioxidant enzyme gene expression. Ann N Y Acad Sci 899: 103-111.

48. O'Brien PJ (1991) Molecular mechanisms of quinone cytotoxicity. Chem Biol Interact 80: 1-41.

49. Das A, Kole L, Wang L, Barrios R, Moorthy B, et al. (2006) BALT development and augmentation of hyperoxic lung injury in mice deficient in NQO1 and NQO2. Free Radic Biol Med 40: 1843-1856

50. Zhang B, Niu W, Xu D, Li Y, Liu M, et al. (2014) Oxymatrine prevents hypoxiaand monocrotaline-induced pulmonary hypertension in rats. Free Radic Biol Med 69: 198-207.

51. Cederberg C, Thomson AB, Mahachai V, Westin JA, Kirdeikis $P$, et al. (1992) Effect of intravenous and oral omeprazole on 24-hour intragastric acidity in duodenal ulcer patients. Gastroenterology 103: 913-918. 